\title{
Detection of Local Wall Stiffness Drop in Steel-Lined Pressure Tunnels and Shafts of Hydroelectric Power Plants Using Steep Pressure Wave Excitation and Wavelet Decomposition
}

\author{
F. E. Hachem, Aff.M.ASCE${ }^{1}$ and A. J. Schleiss ${ }^{2}$
}

\begin{abstract}
A new monitoring approach for detecting, locating, and quantifying structurally weak reaches of steel-lined pressure tunnels and shafts is presented. These reaches arise from local deterioration of the backfill concrete and the rock mass surrounding the liner. The change of wave speed generated by the weakening of the radial-liner supports creates reflection boundaries for the incident pressure waves. The monitoring approach is based on the generation of transient pressure with a steep wave front and the analysis of the reflected pressure signals using the fast Fourier transform and wavelet decomposition methods. Laboratory experiments have been carried out to validate the monitoring technique. The multilayer system (steel-concrete-rock) of the pressurized shafts and tunnels is modeled by a one-layer system of the test pipe. This latter was divided into several reaches having different wall stiffnesses. Different longitudinal placements of a steel, aluminum, and PVC pipe reach were tested to validate the identification method of the weak section. DOI: 10.1061/(ASCE)HY.1943-7900.0000478. (C) 2012 American Society of Civil Engineers.
\end{abstract}

CE Database subject headings: Speed; Tunnels; Pipes; Wave reflection; Hydro power; Power plants; Wavelet; Monitoring; Excitation.

Author keywords: Front wave speed; Steel-lined pressure tunnels; Pipes; Wave reflections; Transient pressure signals; Wavelet decomposition; Monitoring.

\section{Introduction}

In the past, the safety margin for dynamic water pressure loads in steel-lined pressure tunnels and shafts was considered acceptable by using conventional design safety factors. Because of high peak energy demands, existing plants are operating nowadays under rough conditions with relatively fast and numerous valve maneuvers to regulate turbine discharge and power. The economic and social costs attributed to production losses, when these waterconveying structures are emptied for investigations and repairs, are considerable. On the other hand, the failure of such structures produces catastrophic landslides and debris flows and generates a need for repairs with the loss of many years of energy production income.

Traditionally, well-equipped steel-lined shafts and tunnels are monitored by a set of pressure sensors, water level measurements, and downstream-upstream flow meters. Pressure sensing devices are normally used to check the magnitude of the dynamic pressures relative to a predefined serviceability value. No further pressure signal processing is done because the sensors and the acquiring

${ }^{1}$ Researcher-Assistant, Laboratory of Hydraulic Constructions (LCH), Ecole Polytechnique Fédérale de Lausanne (EPFL), Station 18, 1015 Lausanne, Switzerland (corresponding author). E-mail: fadi.hachem@a3 .epfl.ch; fadi.hachem@epfl.ch

${ }^{2}$ Professor and Director, Laboratory of Hydraulic Constructions (LCH), Ecole Polytechnique Fédérale de Lausanne (EPFL), Station 18, 1015 Lausanne, Switzerland. E-mail: anton.schleiss@epfl.ch

Note. This manuscript was submitted on September 13, 2010; approved on June 23, 2011; published online on June 25, 2011. Discussion period open until June 1, 2012; separate discussions must be submitted for individual papers. This paper is part of the Journal of Hydraulic Engineering, Vol. 138, No. 1, January 1, 2012. C)ASCE, ISSN 0733-9429/2012/1-35$45 / \$ 25.00$. system are normally not fast enough to accurately collect highfrequency dynamic signals. If the water flow velocity exceeds a certain threshold, indicating a possible failure, a security shut-off valve closes automatically. This limits the volume of water leaking out from the failure by avoiding the emptying of the tunnel and reservoir upstream of the security valve. Even in this case, catastrophic failure consequences can occur because the volume of leaking water between the valve and the failure location may still be very high. Any additional investigation of the steel liner regarding excessive local deformations and steel yielding requires a dewatering of the conveying system for visual checking. Such inspection is often awkward because of the hostile conditions. Furthermore, no information can be obtained easily about the stiffness of the rock mass surrounding the steel liner.

In addition to these rather rudimentary hydraulic-based monitoring systems, a number of more sophisticated techniques for pipeline failure and leak detection involving transient pressure waves have been applied in water, gas, and oil networks. This began with a development of a sensitivity analysis for leak location processes by Liggett and Pudar (1992). Ferrante and Brunone (2003) used the wavelet transform and its local maxima lines to retain pressure information coming from a time-domain analysis. Al-Shidhani et al. (2003) introduced the identification of pressure wave reflections using the wavelet decomposition. Covas et al. (2005) focused on leakage detection in pipe systems by means of the standing wave difference method. Beck et al. (2005) described a method to detect pipeline features and leaks using the cross-correlation techniques of pressure wave measurements. Misiunas et al. (2005) proposed a continuous monitoring approach on the basis of the timing of the initial and reflected pressure transient waves induced by the break. Fuentes et al. (2006) used the inverse transient-analysis approach with genetic algorithms to find the optimal location of the leak. 
The same approach was adopted by Shamloo and Haghighi (2009) to determine numerically the leak parameters including their number, location, and size. Taghvaei et al. (2010) analyzed experimentally the pressure reflections from the leak using wavelet filtering followed by cepstrum analysis.

From the previous overview, it can be concluded that there is a large number of techniques that can deal with leak detection in pipelines. They all assume that the pressure wave speed is a constant value throughout the pipeline length. Stephens et al. (2008) presented an interesting approach to estimate the location of an internal damage wall of a composite concrete-steel pipeline on the basis of a transient model combined with a genetic algorithm and field measurements. This work is, to the best knowledge of the writers, the only reference found which investigates the wave reflections coming from weak reaches with different hydroacoustic parameters such as wave speed. The altering of the wave speed in pipelines for feature identification application has been also mentioned in Taghvaei et al. (2008).

Therefore, a monitoring method for steel-lined pressure shafts and tunnels is proposed in this paper. It is based on processing the reflection records of steep transient pressure waves in an experimental test pipe. Under an axi-symmetrical behavior, the multilayer system (steel-concrete-rock) of the pressurized shaft can be modeled by a one-layer system. The local deterioration of the backfill concrete and/or the rock zone surrounding the liner results in a so-called weak reach which reduces the overall wave speed and produces reflection boundaries for the incident pressure waves (Hachem and Schleiss 2009). Thus, the test pipe was divided into several reaches having different wall stiffnesses. For the detection of longitudinal stiffness heterogeneity, different geometric configurations of the steel test pipe were examined by systematically changing the position of an aluminum and PVC pipe reach length of $50 \mathrm{~cm}$. For the analysis of the pressure signals, three approaches were used to estimate the wave front speed inside the test pipe. For prediction of the incident-reflection travel time between the weak reach boundaries and the pressure sensor, the fast Fourier transform (FFT) and wavelet decomposition methods were applied.

\section{Theoretical Background}

\section{Basic Equation of Acoustic Plane Waves}

The propagation of sound waves in confined water inside pipes and tunnels is modeled by an equation of motion (conservation of momentum) and an equation of continuity (conservation of mass). Assuming a constant water density, slightly compressible water (low Mach number), and one spatial propagation dimension (along the pipe's longitudinal dimension $x$ ), these equations can be written as follows:

$$
\left\{\begin{array}{l}
\frac{\partial v}{\partial t}+g \frac{\partial h}{\partial x}+f \frac{|v| v}{2 D}=0 \\
\frac{\partial h}{\partial t}+\frac{a^{2}}{g} \frac{\partial v}{\partial x}=0
\end{array}\right.
$$

in which $h(x, t)$ is the piezometric head, $v(x, t)$ is the water-flow velocity, $t$ is the time, $g$ is the acceleration due to gravity, $a$ is the speed of sound in water or the pressure wave velocity, $f$ is the Darcy-Weisbach friction factor, and $D$ is the internal diameter of the tunnel. The differentiation and combination of these two conservation equations leads to the acoustic plane wave equation expressed as (Bergant et al. 2008)

$$
g \frac{\partial^{2} h}{\partial x^{2}}-\frac{g}{a^{2}} \frac{\partial^{2} h}{\partial t^{2}}=-f \frac{|v|}{D} \frac{\partial v}{\partial x}
$$

For a pipe with uniform cross section, the pressure wave velocity can be estimated by the following general formula (Wylie et al. 1993):

$$
a=\sqrt{\frac{1}{\rho_{0}\left(\frac{1}{K_{w}}+\frac{1}{A} \cdot \frac{d A}{d p}\right)}}
$$

in which $d A$ is the variation of the cross-sectional area $A$ of the pipe caused by the variation of the internal water pressure $d p$ and $K_{w}$ is the bulk modulus of water. In steel-lined pressure tunnels and shafts considering neither the fluid-structure interaction (FSI) nor the dynamic effect of the tunnel wall, the ratio $d A / d p$ is a constant value which depends on the geometrical and mechanical characteristics of the steel liner and on the state (cracked or uncracked) of the surrounding backfill concrete and rock mass (Hachem and Schleiss 2011).

In plain strain conditions and considering the hypothesis of linear elasticity and small deformations, Eq. (3) can be written as follows (Halliwell 1963; Streeter 1963; Timoshenko and Goodie 1970):

$$
a=\sqrt{\frac{1}{\rho_{w}\left(\frac{1}{K_{w}}+\frac{2}{r_{i}} \cdot \frac{d u_{r}^{s}(r)}{d p}\right)}}
$$

in which $d u_{r}^{s}(r) / d p$ is the first derivative of the radial displacement of the steel liner $u_{r}^{s}$ relative to the internal pressure $p$ at the waterliner interface of radius $r_{i}$. The $d u_{r}^{s}(r) / d p$ ratio is simply the inverse of the radial stiffness of the tunnel wall. By ignoring the presence of air in water, which can drastically change the pressure wave speed, the velocity of a pressure wave traveling between two cross sections of a tunnel will be affected by every change of the radial stiffness of its wall. In laboratory tests, the change of the wall stiffness can be modeled by using pipe reaches having different $(E \cdot e)$ values than the rest of the test pipe. The value of $E$ is the Young modulus, and $e$ is the thickness of the pipe wall. The general solution of Eq. (2) is the summation of wave propagating at the wave speed $a$ in opposite directions along the tunnel's longitudinal axis.

At tunnel junctions characterized by a change of the hydroacoustic parameters (the flow area $A$ and/or the wave speed $a$ ), an incident wave is reflected and transmitted. Fig. 1 shows the time behavior of a theoretical rectangular wave front propagating in water and crossing two junctions encountered by a pipe reach

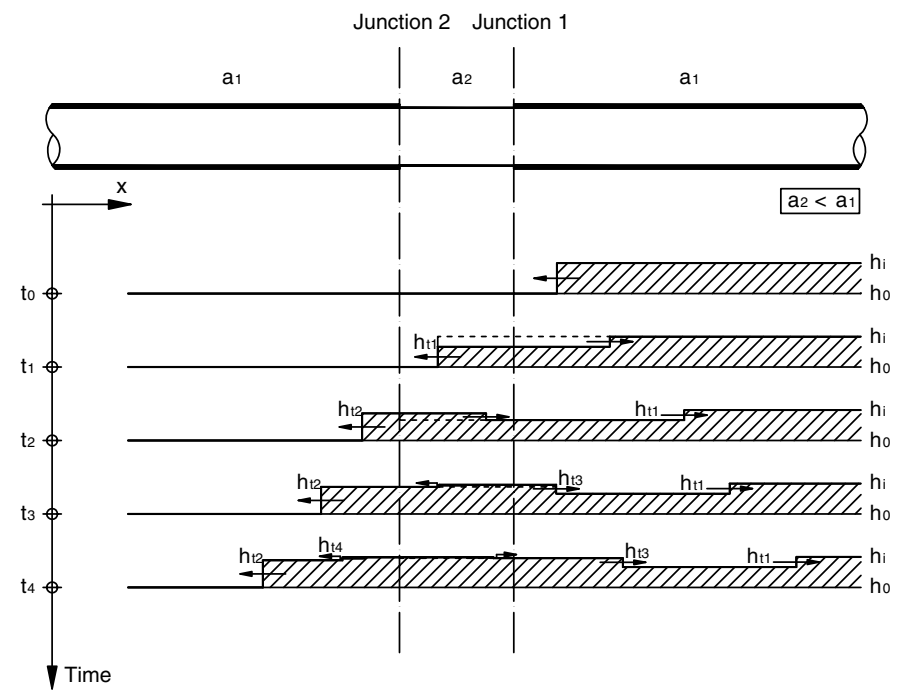

Fig. 1. Theoretical time behavior of a rectangular pressure wave front crossing two junctions that bound a pipe's reach having a wave speed value less than the rest of the pipe 
having a wave speed value $a_{2}$ less than the rest of the pipe $\left(a_{1}\right)$. For steel-lined pressure tunnels, such a decrease of the wave speed can be the consequence of a partial or total loss of the stiffness of the exterior support of the steel liner, which is provided by the surrounding backfill concrete and rock mass. This reach is called weak reach throughout this paper.

According to Fig. 1, an incident pressure wave of magnitude $\left(h_{i}-h_{0}\right)$ is divided into transmitted and reflected waves when crossing Junction 1. For a uniform cross-sectional flow area, the magnitude of the transmitted wave $\left(h_{t 1}-h_{0}\right)$ is given by (Wylie et al. 1993)

$$
h_{t 1}-h_{0}=\frac{2}{1+\frac{a_{1}}{a_{2}}}\left(h_{i}-h_{0}\right)
$$

in which $h_{0}, h_{i}$, and $h_{t 1}$ are the steady-state, incident, and transmitted piezometric heads, respectively. The same phenomenon is reproduced when the pressure wave crosses the downstream end of the weak reach (Junction 2). According to the direction of the first incident wave $h_{i}$, Junctions 1 and 2 are called the upstream and downstream ends of the weak reach.

\section{Pressure Excitations}

The transient pressure excitations inside the water must have enough energy in the wave front to interact with the surrounding walls of the structure even after dissipation during longitudinal propagation. In a hydropower plant, such excitations are generated by the change of the flow rate at the turbines, creating a transient event (Parmakian 1963; Chaudhry 1987). These excitations are repeated many times a day when synchronizing the energy production to the grid demand. Therefore, with a monitoring method based on processing of this type of water transient pressure, a large data base can be acquired. Depending on the flow rate change, a waterhammer with steep front can be generated. Unfortunately, the localization of weak zones becomes difficult for rather slow changes of flow rate. The rising front slope of the incident pressure wave becomes less steep, as well as, the slopes of the partially reflected pressure signal coming back from the weak reach boundaries.

Another artificial type of water pressure excitation could be produced by an explosive shock wave generated in water near the reservoir's intake structure or near the tunnel-shaft junction inside the surge tank. This type of excitation is more risky and complicated to produce than the water-hammer phenomenon resulting from normal operation. Furthermore, the monitoring of shafts and tunnels would have only a limited number of in situ data measurements. The main advantage of such artificial excitation, compared to routine events, is the possibility of generating an incident wave with a steep front, allowing more accurate localization of the weak zones. In this paper, the processing of the transient pressure of laboratory experimental data produced by a steep wave excitation is analyzed.

\section{Localization of Weak Reach on the Basis of Wave Timing}

The location of a weak reach of a steel-lined pressure tunnel can be determined on the basis of the timing of pressure wave reflections that occur at the boundaries of this reach. The travel times of these transient waves can be found by using pressure measurement sampled at high frequency at two points of the waterway. For steel-lined pressure tunnels and shafts, these points are restricted to the accessible reaches of the steel liner. They are normally located inside the valves chambers situated downstream of the reservoir intake, downstream of the surge tank, and at the entrance of the power house. The travel times are then transformed to distances or wave path lengths using the following simple formula:

$$
l=\frac{a \cdot t}{2}
$$

in which $l$ is the distance between the pressure sensor and the boundary of the weak reach and $t$ is the travel time that an incident wave needs to travel from the pressure sensor toward the boundary of the weak reach and to come back, after reflection, to the same sensor's position. To localize the weak reach, a good estimation of the front wave speed and of the incidence-reflection travel time are required.

\section{Estimation of Front Wave Speed $\boldsymbol{a}$}

Three time-based approaches are used to estimate the time of wave travel from the upstream pressure position $(P 1)$ to the downstream one $(P 2)$, with these positions defined according to the direction of the first incident wave $h_{i}$. The values of the front wave speed are then extracted by dividing the known distance separating the two sensors by the estimated travel time.

The first approach extracts the time that separates the maximum values of the front pressure measurements. The second approach determines, for each pressure record, the time at the intersection point of two regression lines correlating the steady-state and the first front pressure data, respectively. The third approach uses the cross-correlation technique to calculate the time lag which separates the front wave lobes of $P 1$ and $P 2$ data. For discrete functions, the cross-correlation is defined as follows (Lange 1987):

$$
(P 2 * P 1)[n]=\sum_{m=-\infty}^{\infty} P 2^{*}[m] \cdot P 1[n+m]
$$

in which $P 2^{*}$ is the complex conjugate of $P 2$ and $n$ and $m$ are positive integers.

A unique value of the front wave speed is finally retained for each test. It is the one of the three wave values obtained from the three approaches which is bounded by the two others.

\section{Estimation of Incident-Reflection Travel Time $t$}

A first approximation of the incident-reflection travel time is obtained by the FFT applied to the pressure records $P 1$ and $P 2$. The FFT gives a global representation of the frequency content of these signals over the entire time domain. For the configurations with weak reach, peaks should occur at the fundamental and harmonic frequencies. They correspond to the wave reflections issuing from the weak reach boundaries.

In the second approach, the results of the FFT approximation combined with the wavelet transform and decomposition techniques are used to localize more accurately the boundaries of the weak reach. One pressure record is sufficient to estimate the incident-reflection travel time between the pressure sensor's position and these boundaries. Wavelets are mathematical functions that decompose a signal into its constituent parts using a family of wavelet basis functions created both by dilations (scaling) and translations (in time) of a mother wavelet (Mallat 1990). The continuous wavelet transform coefficients, $W f(u, s)$, are obtained by convolving the signal $f(t)$ with the translations $u$ and dilations $s$ of the complex conjugate $\psi_{u, s}^{*}$ of the mother wavelets $\psi_{u, s}$, according to the following equation:

$$
W f(u, s)=\int_{-\infty}^{+\infty} f(t) \cdot \psi_{u, s}^{*} d t
$$

in which the mother wavelets $\psi_{u, s}$ are generated by

$$
\psi_{u, s}(t)=\frac{1}{\sqrt{s}} \psi\left(\frac{t-u}{s}\right)
$$


In discrete analysis and for discrete signals of finite energy, the reconstruction of the signal $f(t)$ is performed by using the inverse wavelet transform

$$
f(t)=\sum_{j \in \mathbb{Z}} \sum_{k \in \mathbb{Z}} W f(k, j) \cdot \psi_{k, j}(t)
$$

in which $j$ is the scale index or the decomposition level $\left(s=2^{j}\right)$ and $k$ is the time index $\left(u=k \cdot 2^{j}\right)$. By fixing $j$ and summing over $k$, the detail coefficient at level $j, D_{j}$, is defined by

$$
D_{j}(t)=\sum_{k \in \mathbb{Z}} W f(k, j) \cdot \psi_{k, j}(t)
$$

The signal $f(t)$ is thus the sum of its wavelet details at different levels $j$. By considering a reference decomposition level $J$, the approximation coefficient at this level is

$$
A_{J}(t)=\sum_{j>J} D_{j}(t)
$$

A wavelet decomposition tree up to level four is shown in Fig. 2, where $A_{i}$ and $D_{i}$ are the $i$ th-level approximation and detail coefficients, respectively. After $j$ levels of decomposition, the original signal $f(t)$ can be finally expressed as

$$
f(t)=A_{j}+\sum_{i=1}^{j} D_{i}
$$

In this work, the Daubechies wavelet (db10), shown in Fig. 3, is used for the family of basis functions. The numerical index refers to the order or number of coefficients of the wavelet. The db10 doesn't have an explicit expression. Its central frequency is equal to $0.68421 \mathrm{~Hz}$.

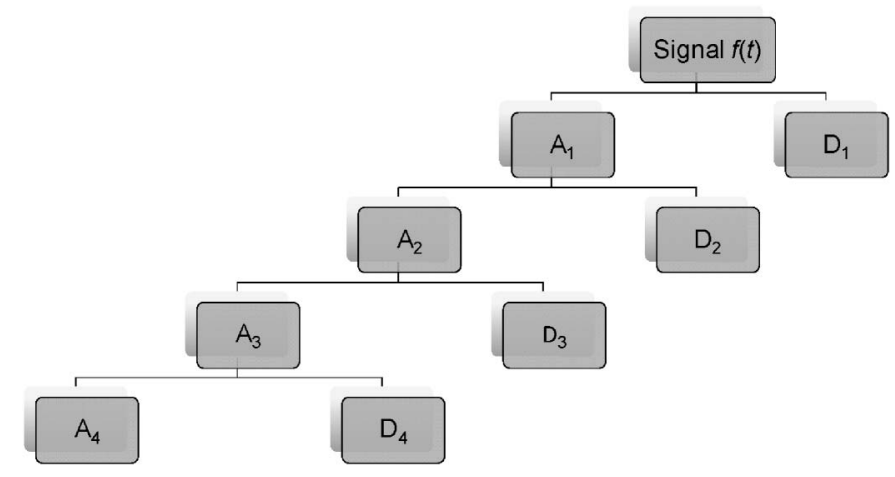

Fig. 2. Wavelet decomposition tree up to level four where, $A_{1}, A_{2}, A_{3}$, and $A_{4}$ are the approximations and $D_{1}, D_{2}, D_{3}$, and $D_{4}$ are the details

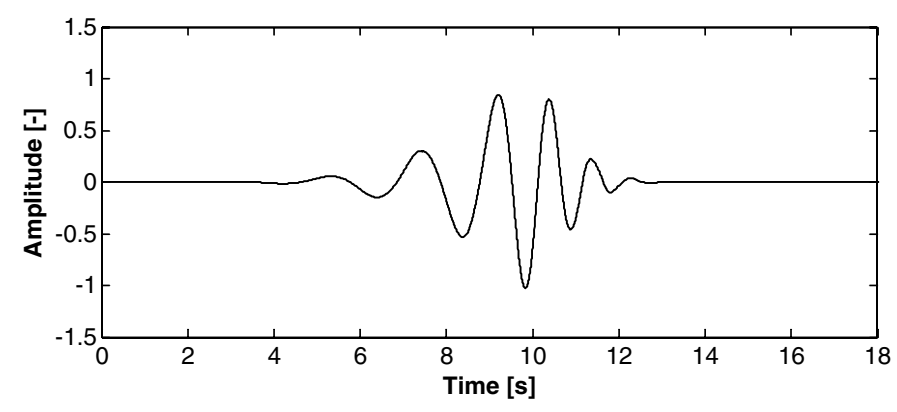

Fig. 3. Daubechies (db10) wavelet basis

\section{Experimental Tests and Data Analysis}

\section{Experimental Setup}

An experimental facility was assembled at the Laboratory of Hydraulic Machines of EPFL (Ecole Polytechnique Fédérale de Lausanne). This facility was specially designed for detecting the change of wall stiffness of a test pipe using recorded pressure data generated either by an external water pressure excitation source or by a rapid change of the flow rate's producing water-hammer phenomena inside the pipe. This paper deals with pressure measurements obtained from an external water pressure excitation.

The configuration of the experimental setup is shown in Fig. 4. It consists of a test pipe with an internal diameter of $150 \mathrm{~mm}$ and a length of $6.25 \mathrm{~m}$ measured from the shut-off valve to the upstream air vessel. The pipe is supplied with water by a reservoir and a variable speed pump. It is divided into several reaches of 0.5 and $1.0 \mathrm{~m}$ lengths fitted together with flanges having an external diameter of $285 \mathrm{~mm}$ and a thickness of $24 \mathrm{~mm}$. The flanges are also used to rigidly fix the test pipe along its length to minimize any longitudinal and transversal movements during test events. On the $10-\mathrm{m}$ supply conduit, an electromagnetic flow meter is placed to measure the steady-state flow. On the highest point of this conduit, an air purge valve is installed to evacuate the captured air inside the test rig. A first control and security valve followed by an elastic deformable joint (TUBOFLEX) are located at the downstream end of the supply conduit, which is protected against water-hammer phenomena by a pressurized air vessel. The downstream end of the test pipe is equipped with a shut-off valve operated by an air jack. It is followed by a purge valve, two elbows, an elastic TUBOFLEX joint, and a second control valve located at the entrance of the supply reservoir. The total length of all these pieces is approximately $2 \mathrm{~m}$. The external pressure excitation, transmitted to the water through the jack axis, and the closure of the shut-off valve are carried out automatically by the air jack with input and output electrovalves. The volume of air needed to activate the jack is provided by an air compressor with a constant pressure of $1.05 \mathrm{kPa}$ (10 bars). The state of the shut-off valve is detected by two diffuse sensors with an infrared beam. The data acquisition system includes (1) two pressure transducers (HKM-375M-7-BAR-A, Kulite) with a pressure range from 0 to $0.735 \mathrm{kPa}$ ( 0 to 7 bars) and an accuracy of $0.5 \%$, (2) an NI-USB-6259 acquisition card $M$ series with 32 analog input channels and two analog output channels to activate the two electrovalves of the shut-off valve, and (3) a notebook computer connected to the acquisition card through a universal serial bus (USB) cable. The sampling frequency was fixed to $f_{s}=15 \mathrm{KHz}$. LabView 8.6, MATLAB 2008b, and Diadem 11.0 software were used for acquiring, controlling, and processing the experimental data.

\section{Test Pipe Configurations}

Five pipe configurations were tested with approximately the same initial steady flow conditions of 58.5, the same air pressure in the compressor $1.05 \mathrm{kPa}$ (10 bars), and the same mean pressure at the entrance of the test pipe of around $0.021 \mathrm{kPa}(0.2 \mathrm{bar})$. The basic configuration of the test pipe, named Steel, corresponds to steel pipe reaches of 100 and $50 \mathrm{~cm}$ length with $4.5 \mathrm{~mm}$ wall thickness arranged in a basic configuration according to Fig. 5. In the configuration "Steel+Alu1", the first $50 \mathrm{~cm}$ pipe reach (the first pipe reach is that nearest the air vessel) is replaced by an aluminum pipe with $5 \mathrm{~mm}$ wall thickness. In the configurations "Steel+PVC1", "Steel+PVC2", or "Steel+PVC3," the first, second or third $50 \mathrm{~cm}$ long pipe reach is replaced by a $5 \mathrm{~mm}$ thick PVC pipe. For each test pipe configuration, many repetitive tests were carried out, giving a 

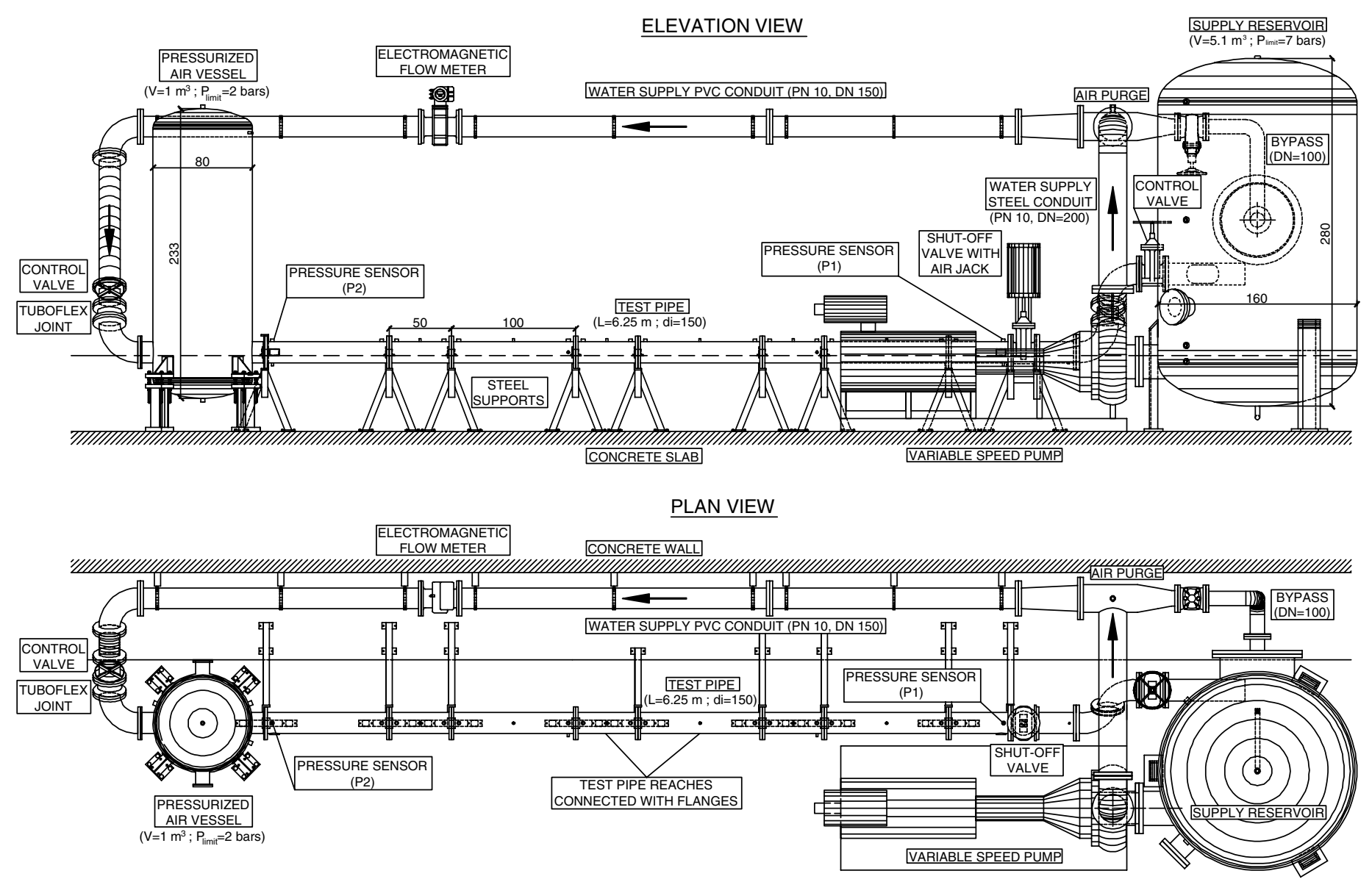

Fig. 4. Elevation and plan views of the experimental facility

total number of 67 tests (19 for Steel, 6 for "Steel+Alu1", 18 for "Steel+PVC1", 12 for "Steel+PVC2", and 12 for "Steel+PVC3"). The theoretical radial stiffness $(E \cdot e)$ of steel, aluminum, and PVC reaches are 945,345 and $15 \mathrm{MN} / \mathrm{m}$, respectively.

\section{Weak Reach Localization}

In Fig. 6(a) five records of the transient water pressure, $P 1$, for the five different configurations of the test pipe are shown. These transient pressures are caused by the impact of the pressurized air on the jack piston. This excitation is transmitted to water inside the test pipe by means of the jack axis. Fig. 6(b) depicts the five pressure signals, $P 2$, for the same tests.

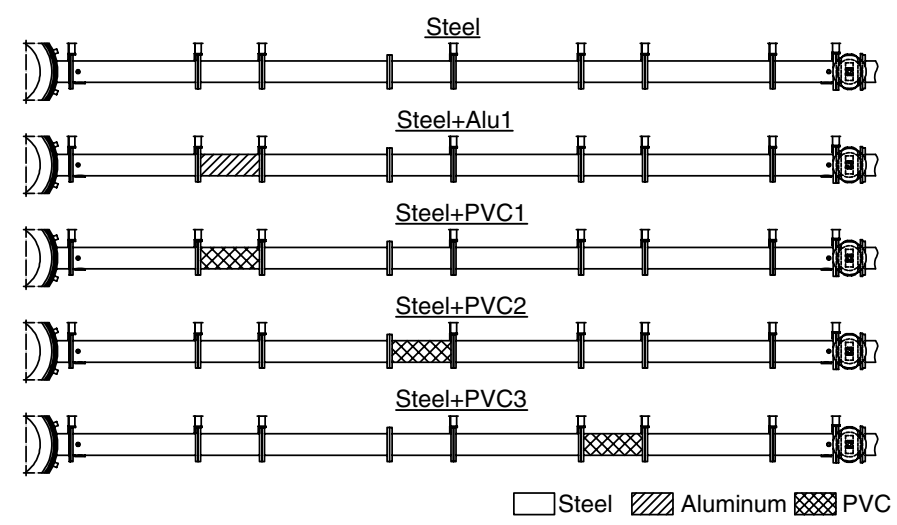

Fig. 5. Five different configurations of the test pipe
The front wave speeds $a$ of all the 67 tests have been computed using the three approaches presented in the "Estimation of Front Wave Speed $a$ " section. In Fig. 7, the mean and the standard deviation of $a$ for each pipe configuration are shown. Because of the low values of the standard deviation (below $11.7 \mathrm{~m} / \mathrm{s}$ ) and the clear differences observed between the mean wave speed of Steel and Steel+PVC configurations, it may be concluded that the wave speed computed according to the three approaches using the dynamic pressure records at both ends of the test pipe can be considered as a global indicator of large changes in the stiffness of the pipe wall (relative changes $\left[(E \cdot e)_{\mathrm{PVC}}-(E \cdot e)_{\text {Steel }}\right] /(E \cdot e)_{\text {Steel }}$ near $98 \%)$. This conclusion is consistent with previous statements in the literature (Hunaidi 2006). For the test pipe configurations with a $50 \mathrm{~cm}$ aluminum reach having an $(E \cdot e)$ value equal to $345 \mathrm{MN} / \mathrm{m}$, the drop of the wave speed values relative to the Steel configurations is small.

A first approximation of the incident-reflection travel time $t$ is performed using the FFT with Hanning windowing. The normalized FFT density spectra of all the tests signals $P 1$ and $P 2$ are computed. The normalization is obtained by dividing all the FFT magnitudes by the magnitude computed at $100 \mathrm{~Hz}$. This frequency corresponds to the incident-reflection travel time between the weak reach at position 1 and the downstream reservoir. Fig. 8 shows an example of the normalized FFT for the $P 1$ [Fig. 8(a)] and $P 2$ [Fig. 8(b)] signals shown in Figs. 6(a) and 6(b). The first fundamental frequencies, $f_{\max , P 1}$ for $P 1$ and $f_{\max , P 2}$ for $P 2$ more than $100 \mathrm{~Hz}$, should be used. They are the lowest peak frequencies of each record obtained after discarding the fundamental and harmonic frequencies of the other one. These values are also shown on 

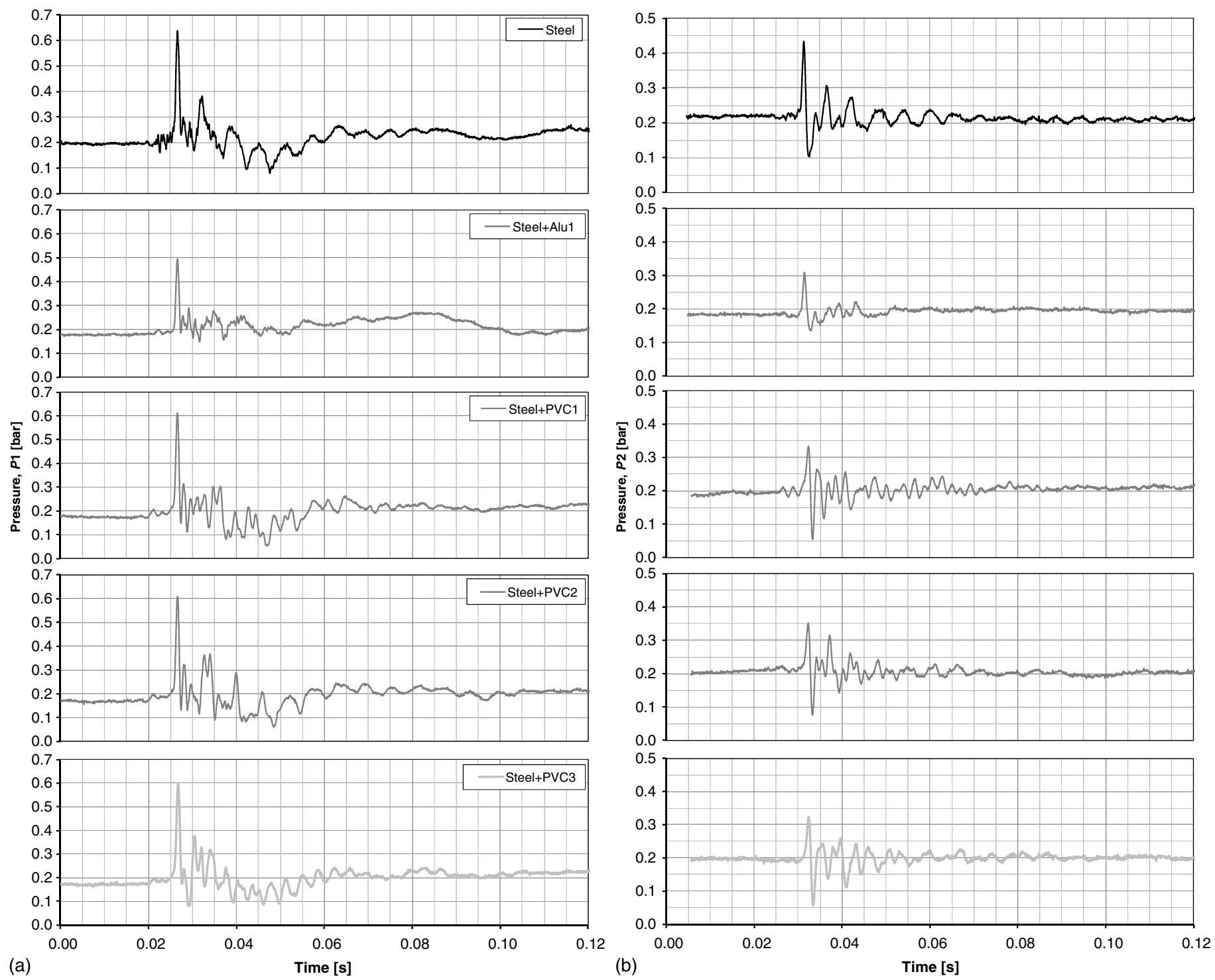

Fig. 6. Records of transient water pressure for five configurations of the test pipe: (a) $P 1$ records; (b) $P 2$

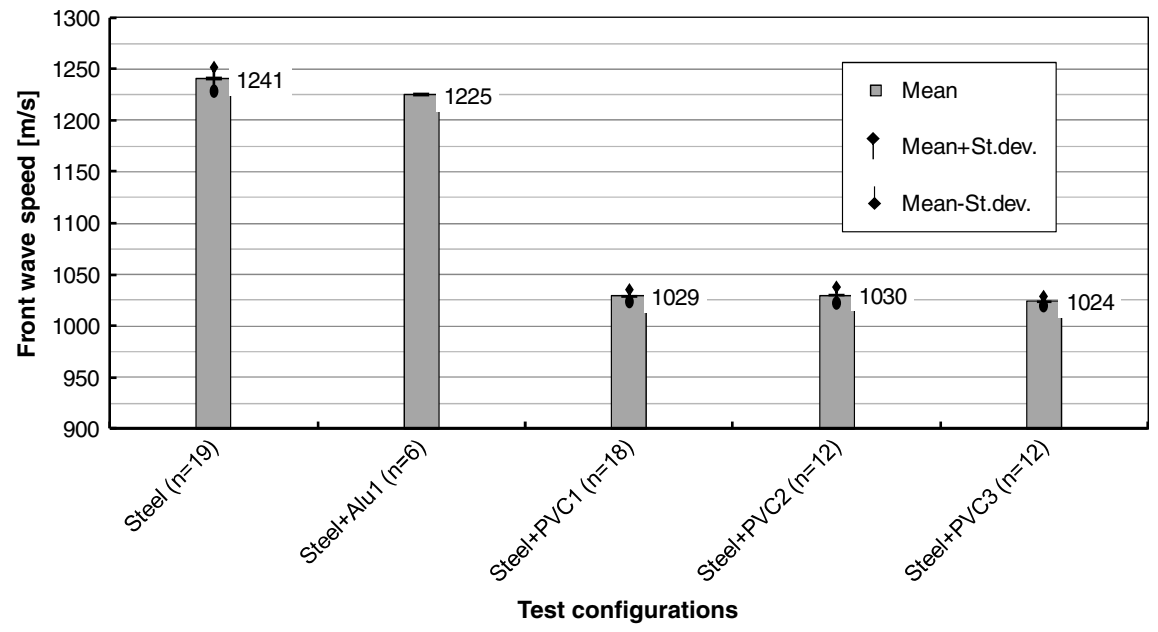

Fig. 7. Mean and standard deviations of the front wave speed for each test pipe configuration 

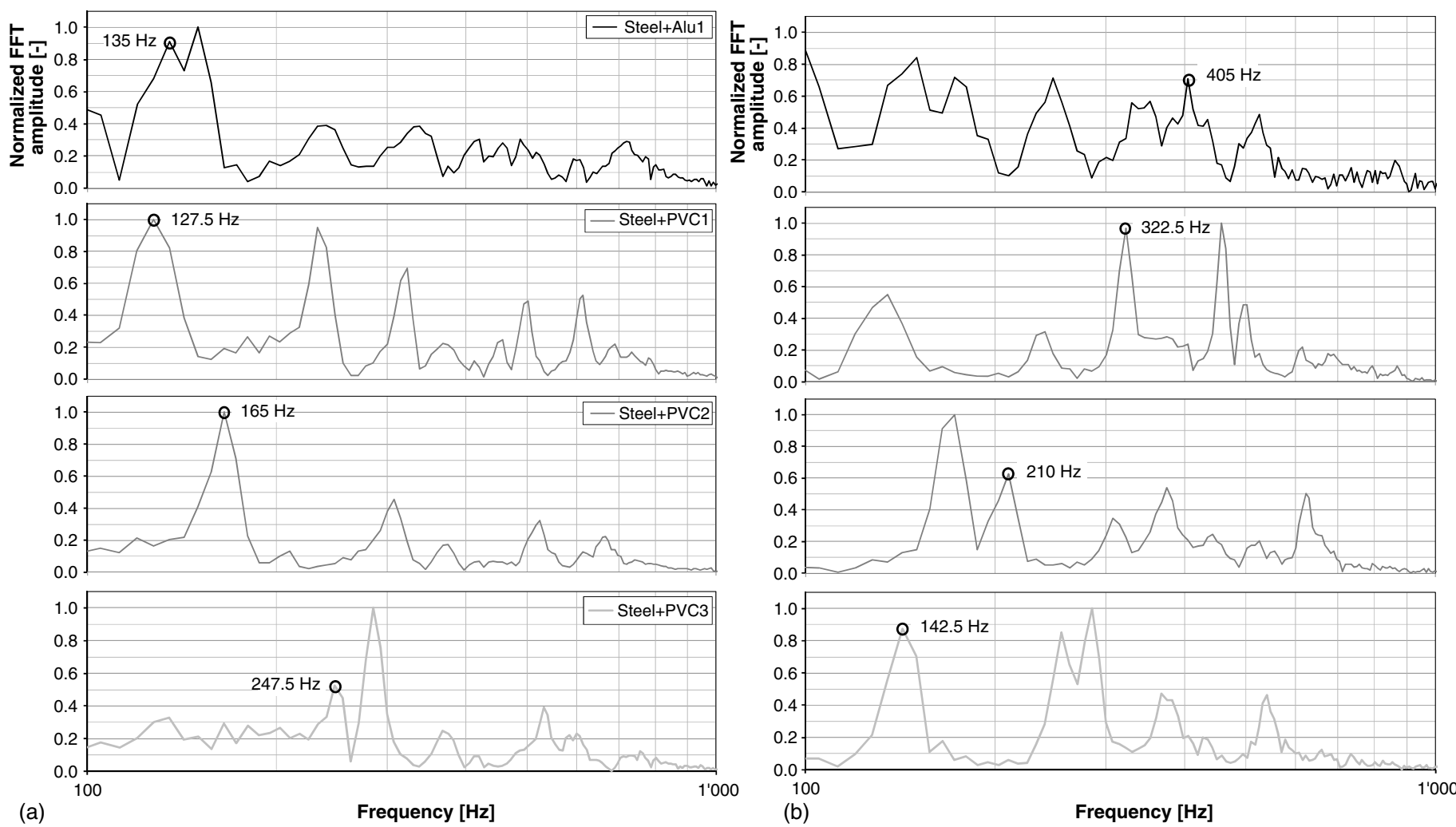

(a)

Frequency $[\mathrm{Hz}]$ (b)

Frequency $[\mathrm{Hz}]$

Fig. 8. Normalized FFT of the test pipe configurations with weak reach: (a) FFT of the $P 1$ records as shown in Fig. 6(a); (b) FFT of the $P 2$ records as shown in Fig. 6(b)

Figs. 8(a) and 8(b). The estimation of the incident-reflection travel distances, $L_{1}$ and $L_{2}$, between the weak reach and the downstream and upstream reservoirs, respectively, is done according to Eq. (6) using the wave speed of the Steel configuration. The reflections from the two elbows and the elastic joint downstream from the shut-off valve have altered the estimation of $L_{1}$ by approximately 12 to $23 \%$. Therefore, the $L_{2}$ distance was used to correct $L_{1}$ and to determine the estimated distance between the pressure sensor $P_{1}$ and the weak reach. This travel distance and the error relative to the real path length are presented in Table 1. The FFT approach can roughly predict the position of the weak reach with one path length relative to the pressure sensor. The error in predicting the position of the weak reach relative to the real position of its middle varies from 2.3 to $33.0 \%$. It should be mentioned here that the identification of the fundamental frequencies for the "Steel
+Alu1" configuration was difficult and uncertain because of the presence of many peaks. That is why they are written between parentheses in Table 1.

To more accurately localize the weak reach, the wavelet transform and decomposition techniques are applied to pressure signal $P 1$. The decomposition at level $j$ is related to the wavelet scale factor $s$ by $s=2^{j}$. For a sampling time step of $1 / f_{s}$, the scale is associated to a pseudofrequency $f_{a}$ by

$$
f_{a}=\frac{f_{c} \cdot f_{s}}{s}
$$

in which $f_{c}$ is the central frequency of the $\mathrm{db} 10$ wavelet $(=0.68421 \mathrm{~Hz})$. In low-dispersion media, the shifts in the water pressure signals caused by reflections have slope values close to

Table 1. Distances between Weak Reach Boundaries and Sensors $P 1$ and $P 2$ Estimated according to FFT Approach

\begin{tabular}{|c|c|c|c|c|c|c|c|}
\hline $\begin{array}{l}\text { Test pipe } \\
\text { configuration }\end{array}$ & Path & $\begin{array}{l}\text { Real path length } \\
\text { to middle of } \\
\text { the WR } \\
{[\mathrm{m}]}\end{array}$ & $\begin{array}{c}\text { Estimated mean } \\
\text { wave speed } \\
{[\mathrm{m} / \mathrm{s}]}\end{array}$ & $\begin{array}{c}\text { Estimated } \\
\text { fundamental } \\
\text { frequency } \\
{[\mathrm{Hz}]}\end{array}$ & $\begin{array}{c}\text { Estimated } \\
\text { incident-reflection } \\
\text { travel time } \\
{[\mathrm{s}]}\end{array}$ & $\begin{array}{c}\text { Predicted } \\
\text { path length } \\
{[\mathrm{m}]}\end{array}$ & $\begin{array}{c}\text { Relative error } \\
\text { on path length } \\
{[\%]}\end{array}$ \\
\hline \multirow[t]{2}{*}{ Steel+Alu1 } & $\mathrm{P} 1-\mathrm{WR}^{\mathrm{a}}$ & 4.69 & \multirow[t]{2}{*}{1225.26} & (135.0) & 0.007653 & 4.71 & $(0.4)$ \\
\hline & P2-WR & 1.19 & & (405.0) & 0.001901 & 1.17 & $(1.7)$ \\
\hline \multirow[t]{2}{*}{ Steel+PVC1 } & P1-WR & 4.69 & \multirow[t]{2}{*}{1025.82} & 127.5 & 0.006896 & 4.30 & 8.4 \\
\hline & P2-WR & 1.19 & & 322.5 & 0.002541 & 1.58 & -33.0 \\
\hline \multirow[t]{2}{*}{ Steel+PVC2 } & P1-WR & 3.19 & \multirow[t]{2}{*}{1037.95} & 165.0 & 0.005236 & 3.26 & -2.3 \\
\hline & P2-WR & 2.69 & & 210.0 & 0.004200 & 2.62 & 2.7 \\
\hline \multirow[t]{2}{*}{ Steel+PVC3 } & P1-WR & 1.69 & \multirow[t]{2}{*}{1025.84} & 247.5 & 0.002980 & 1.86 & -9.9 \\
\hline & P2-WR & 4.19 & & 142.5 & 0.006456 & 4.02 & 4.4 \\
\hline
\end{tabular}

${ }^{\mathrm{a}} \mathrm{WR}$ stands for Weak Reach. 
the front slope of the incident wave. To capture accurately these shifts in the time domain, an appropriate decomposition level with a pseudofrequency near but more than the quarter-frequency of the wave front should be used. The latter frequency is estimated according to the following equation:

$$
f_{\frac{1}{4} \text { front }}=\frac{1}{4\left(t_{\max }-t_{\text {int }}\right)}
$$

in which $t_{\max }$ is the time of the maximum front pressure and $t_{\text {int }}$ is the time of the intersection point of two regression lines correlating, respectively, the steady-state and the first front pressure signal. The mean quarter-frequency of the incident waves generated during laboratory tests is equal to $357 \mathrm{~Hz}$. From Eq. (13) it can be concluded that level 4 (with a pseudofrequency of $641.4 \mathrm{~Hz}$ ) should be used. The detail $D_{4}$ associated with the approximation $A_{4}$ is then investigated to find the incident-reflection travel time, $t$.

In Fig. 9, an example of the normalized graphs (normalization relative to their maximum values) of $A_{4}$ and $D_{4}$ for the four pipe configurations is given. A window between times 0.02 and $0.05 \mathrm{~s}$ of the wavelet decomposition-level 4 is shown for the pressure records $P 1$ presented in Fig. 6(a). The two slopes that limit the negative pressure shifts caused by reflections from the weak reach boundaries are time-located by two positive peaks of $D_{4}$. The shifts themselves mark $A_{4}$ with minimum peaks. Therefore, the incidentreflection travel time of each weak reach boundary corresponds to the difference between the maximum peak time of $D_{4}$ that bounds a minimum peak of $A_{4}$ and the time when the pressure wave front passes through $P 1$. The time $t_{\text {int }}$ of the front wave pressure $P 1$ is taken as the time origin to locate the upstream boundary. The time $t_{\max }$ at the maximum pressure of the wave front is considered as the origin of time to locate the downstream boundary. The incidentreflection travel time between the pressure sensor $P_{1}$ and the weak reach estimated from the FFT approach is used to localize the adequate $A_{4}$ minimum peak relative to the maximum pressure of the wave front. The maximum peaks of $D_{4}$ that bound this $A_{4}$ minimum correspond to the two slopes of the negative shifts caused by reflections from the weak reach boundaries. The $D_{4}$ maximum peaks are marked by vertical lines on Fig. 9. The estimated values of the incident-reflection times, the position of the weak reach boundaries, and the relative error are given in Table 2. The transformation of the incident-reflection time to distance for the upstream boundary is performed with the mean front wave speed of the Steel configuration. The downstream boundary distance is calculated using the front speed of the tested configuration between the two boundaries and the front speed of the Steel configuration for the rest of the path length. The errors on distances relative to the real values vary between 0.7 and 8.2\%. In Figs. 10(a) and 10(b), the means and the standard deviations of distances between the boundaries of the weak reach and the position of the pressure sensor $P 1$ are given. These statistical parameters are computed using the data of the 48 tests in which a weak reach of aluminum or PVC is used. The highest relative error of approximately $7 \%$ occurs

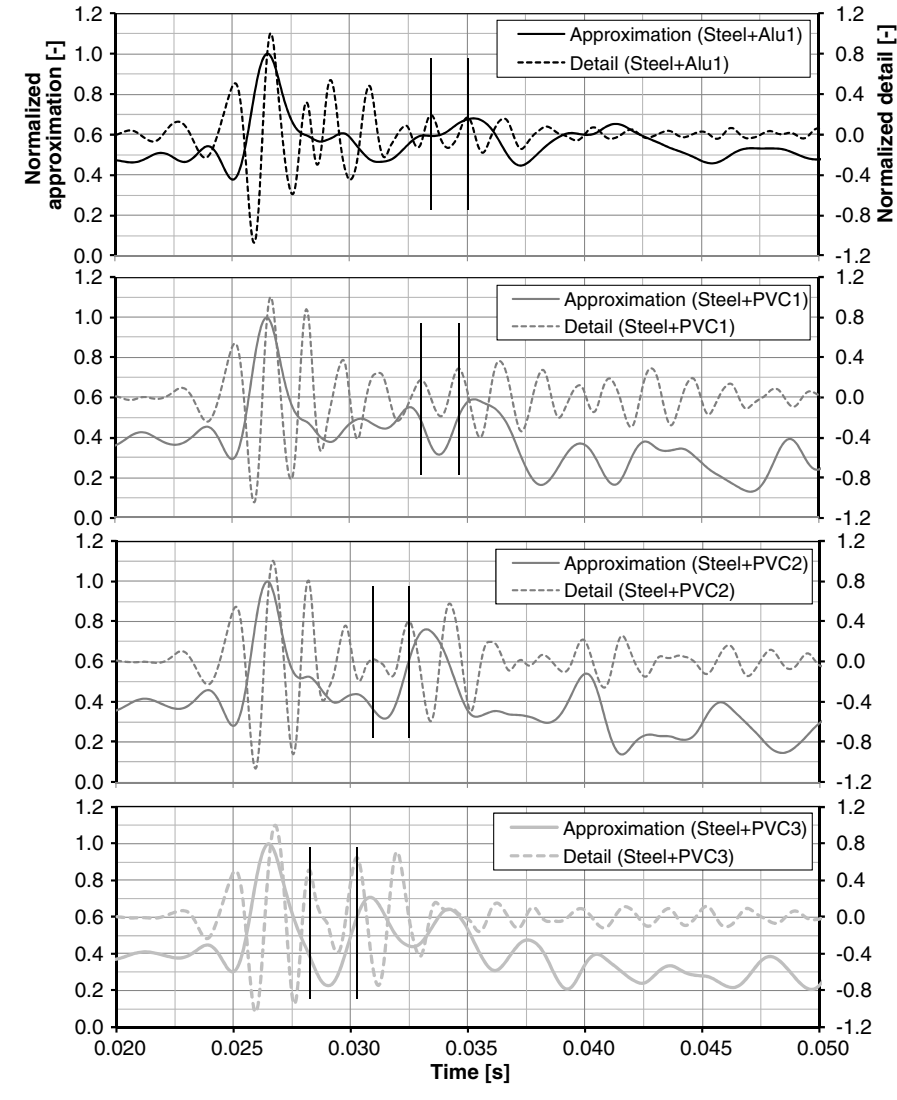

Fig. 9. Normalized wavelet approximations and details (level 4) of the transient water pressures $P 1$ shown in Fig. 6(a) for five configurations of the test pipe; the vertical lines indicate the time position of the two slopes that limit the reflected pressure shifts

when localizing the weak reach in the middle of the test pipe. The relative mean error for the localization of the upstream and downstream boundaries of "Steel+Alu1", "Steel+PVC1", "Steel +PVC2", and "Steel+PVC3" configurations are significantly small and are equal to $3.5,1.1,5.7$, and $-1.5 \%$, respectively.

\section{Stiffness of the Weak Reach}

The stiffness $(E \cdot e)_{W R}$ of the weak reach of the test pipe can be estimated using the wave speed relation for pipes and open penstocks. This relation is derived from Eq. (4) and can be written, after rearrangement, as follows:

$$
(E \cdot e)_{W R}=\frac{2 \cdot r_{i} \cdot \lambda_{3}}{\frac{1}{\rho_{w} \cdot a_{W R}^{2}}-\frac{1}{K_{w}}}
$$

in which

$$
\lambda_{3}= \begin{cases}1-0.5 \cdot \nu_{s} & \text { if the penstock can freely slip in the longitudinal direction } \\ 1 & \text { if the penstock has expansion joints over its entire length } \\ 1-\nu_{s}^{2} & \text { if the penstock is blocked in the longitudinal direction }\end{cases}
$$

$a_{W R}$ is the front wave speed in the confined water inside the weak reach, and $\nu_{s}$ is Poisson's ratio for steel. The only unknown parameter in Eq. (4) is $a_{W R}$. It can be calculated by using the estimated value of the wave speed between sensors $P 1$ and $P 2$ and the estimated length of the weak reach. This is done according to the following equation: 
Table 2. Distances between Weak Reach Boundaries and Sensors $P 1$ Estimated according to Wavelet Decomposition Approach

\begin{tabular}{|c|c|c|c|c|c|c|}
\hline $\begin{array}{l}\text { Test pipe } \\
\text { configuration }\end{array}$ & Path & $\begin{array}{l}\text { Real path } \\
\text { length } \\
{[\mathrm{m}]}\end{array}$ & $\begin{array}{l}\text { Estimated } \\
\text { mean wave } \\
\text { speed } \\
{[\mathrm{m} / \mathrm{s}]}\end{array}$ & $\begin{array}{c}\text { Estimated } \\
\text { incident-reflection } \\
\text { travel time } \\
{[\mathrm{s}]}\end{array}$ & $\begin{array}{l}\text { Predicted path } \\
\text { length } \\
{[\mathrm{m}]}\end{array}$ & $\begin{array}{c}\text { Relative error } \\
\text { on the path } \\
\text { length } \\
{[\%]}\end{array}$ \\
\hline \multirow[t]{2}{*}{ Steel+Alu1 } & P1-UWR ${ }^{a}$ & 4.44 & \multirow[t]{2}{*}{1225.26} & 0.007465 & 4.59 & 3.49 \\
\hline & P1-DWR ${ }^{b}$ & 4.94 & & 0.008331 & 5.13 & 3.75 \\
\hline \multirow[t]{2}{*}{ Steel+PVC1 } & P1-UWR & 4.44 & \multirow[t]{2}{*}{1025.82} & 0.007073 & 4.41 & -0.73 \\
\hline & P1-DWR & 4.94 & & 0.007998 & 4.88 & -1.17 \\
\hline \multirow[t]{2}{*}{ Steel+PVC2 } & P1-UWR & 2.94 & \multirow[t]{2}{*}{1037.95} & 0.004968 & 3.10 & -5.29 \\
\hline & P1-DWR & 3.44 & & 0.005799 & 3.53 & -2.52 \\
\hline \multirow[t]{2}{*}{ Steel+PVC3 } & P1-UWR & 1.44 & \multirow[t]{2}{*}{1025.84} & 0.002291 & 1.43 & -0.86 \\
\hline & P1-DWR & 1.94 & & 0.003599 & 2.10 & 8.17 \\
\hline
\end{tabular}

${ }^{\mathrm{a}} \mathrm{UWR}=$ upstream boundary of the weak reach.

${ }^{\mathrm{b}} \mathrm{DWR}=$ downstream boundary of the weak reach.

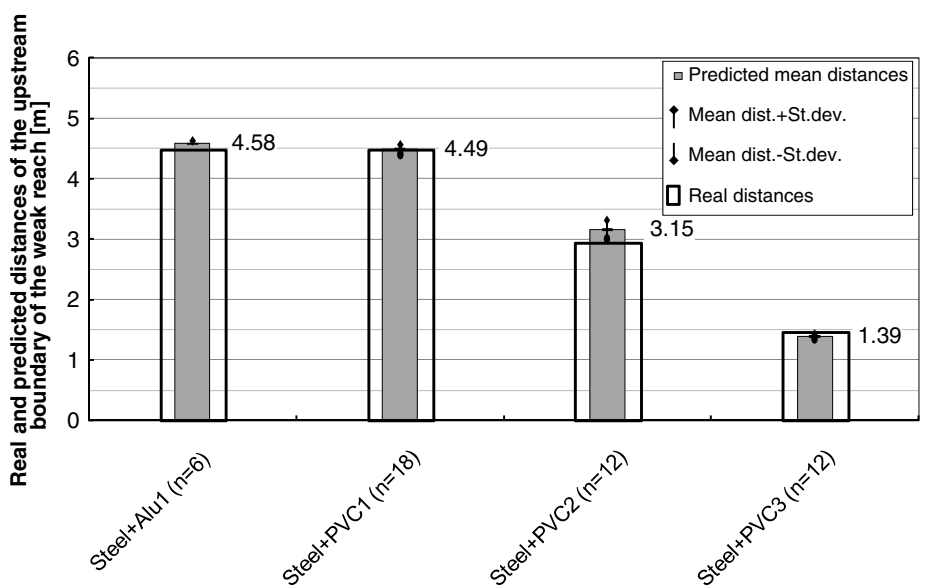

(a)

Test configurations

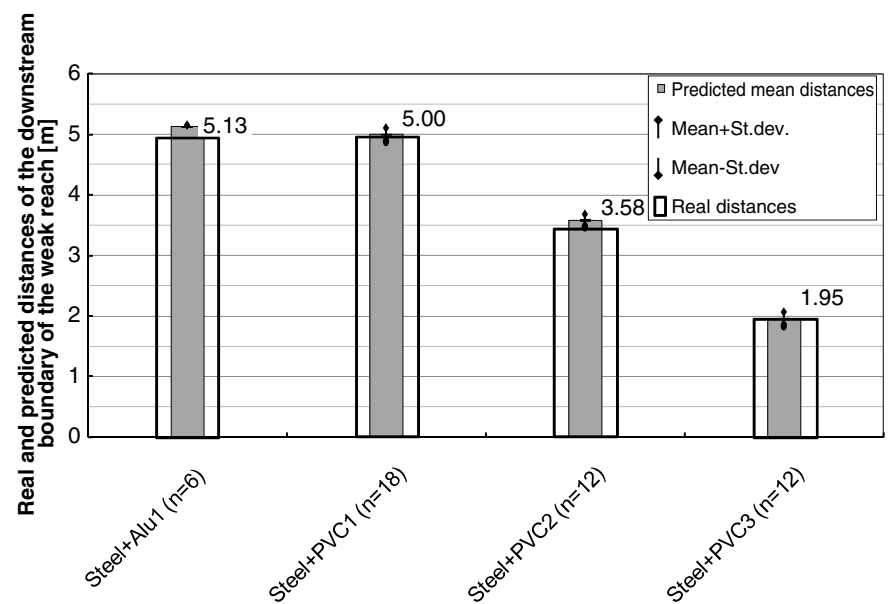

(b)

Test configurations

Fig. 10. Comparison of real and mean predicted distances separating the weak-reach boundaries from the sensor position $P 1$; the standard deviations of these distances computed for all 48 tests with weak reach are also shown: (a) for the upstream boundary, and (b) for the downstream boundary

$$
a_{W R}=\frac{l_{W R}}{\frac{d_{P 1, P 2}}{a_{P 1, P 2}}-\frac{\left(d_{P 1, P 2}-l_{W R}\right)}{a_{\text {basic }}}}
$$

in which $l_{W R}$ is the estimated length of the weak reach, $a_{P 1, P 2}$ is the estimated front wave speed of the test pipe configuration with weak reach $d_{P 1}, P 2$ is the distance separating the two sensors positions, and $a_{\text {basic }}$ is the mean front wave speed of the basic test pipe configuration. The real and estimated stiffness of the weak reach for the tested pipe configurations are given in Fig. 11 for the pressure records of Figs. 6(a) and 6(b). The big differences between the stiffness of Steel and Steel+PVCs configurations make the log scale for the vertical axis of Fig. 11 necessary to show clearly the points relative to the configurations tested. Also, the estimated mean stiffness of the Steel configuration is shown. It is determined by averaging the values obtained from Eq. (4) in which $a_{W R}$ is replaced by the steel front wave speed between $P 1$ and $P 2$. The real stiffness for this configuration is the product of the steel Young's modulus of $210,000 \mathrm{MPa}$ and the thickness of the steel pipe wall of $4.5 \mathrm{~mm}$. In Fig. 11, the following input values have been used:

$$
\begin{array}{lrl}
r_{i}=75 \mathrm{~mm} & K_{w}=2,200 \mathrm{MPa} & \rho_{w}=1,000 \mathrm{~kg} / \mathrm{m}^{3} \\
\nu_{s}=0.30 & \nu_{\mathrm{Alu}}=\nu_{\mathrm{PVC}}=0.40 & \lambda_{3}=1-\nu_{s, \mathrm{Alu}, \mathrm{PVC}}^{2}
\end{array}
$$

In Fig. 12, the mean and the standard deviation of the stiffness of the weak reach is shown for each test pipe configuration. A maximum relative mean error of approximately $33.5 \%$ is observed for the "Steel+Alu1" test pipe configuration. For the "Steel+PVC1",

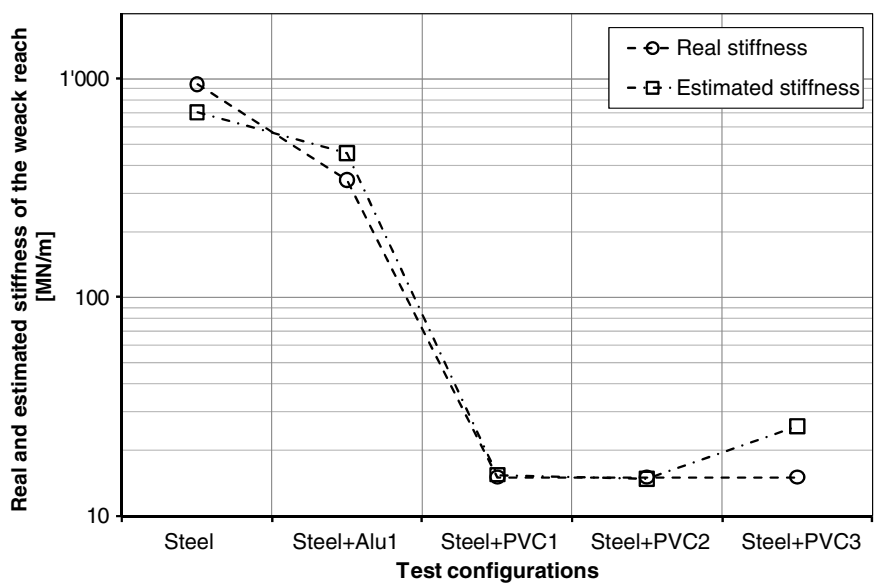

Fig. 11. Real and estimated stiffness of the weak reach for the test pipe configurations whose pressure records are given in Fig. 6 


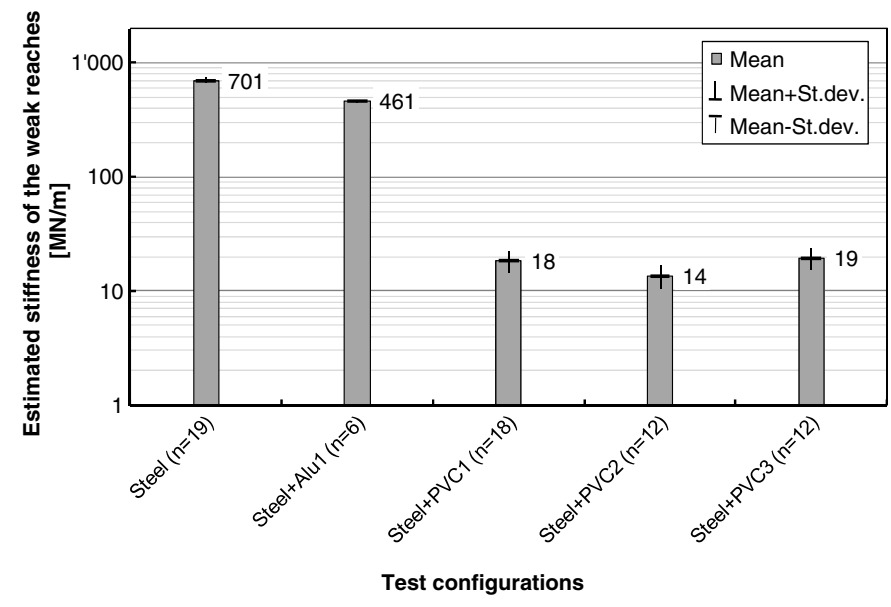

Fig. 12. Mean and standard deviations of the estimated stiffness of the weak reach for each test pipe configuration

"Steel+PVC2", and "Steel+PVC3" configurations, these relative mean errors are $22.6,-9.7$, and $29.2 \%$, respectively.

\section{Conclusions}

A new technique to detect the position and severity of a stiffness change in pipe walls is suggested and validated with experiments. It combines the FFT and the wavelet decomposition techniques of water pressure records at two measurement sections of the test pipe. The signal-processing procedure was applied successively on 67 tests by using a pressure excitation source with steep wave front. The following points may be concluded:

1. The measured water transient pressures at two end positions of the test pipe can be used to predict the front wave speed of an excitation traveling between them. Three different methods were applied to estimate this crucial parameter required in the time-distance transformation process. They are based on (1) the determination of the time separating the maximum front peaks of the signals, (2) the time separating the intersection point of the regression line for the steady-state pressure and the regression line for the first pressure front, and (3) the cross-correlation method. It showed that this parameter could be a global indicator of large changes in stiffness (stiffness decreases down to $98 \%$ ) of the pipe wall.

2. It is possible to extract useful information from the reflected pressure signals induced by the boundaries of a weak reach of the test pipe. The localization routine of the weak reach begins with an FFT analysis of the two measured pressure signals. This allows a rough approximation (between 2.3 and $33.0 \%$ ) of the middle position of the weak reach. The time obtained by this approach is used to choose the appropriate peaks in the details and approximations of the wavelet decomposition of one measured signal. This latter analysis predicts very well the position of the weak reach boundaries with a maximum relative mean error of $5.7 \%$.

3. Once the length of the weak reach is found, the severity of the local stiffness change of the pipe wall can also be estimated by using the standard wave speed equation inside the weak reach. This wave speed is determined from the predicted length of the weak reach and the estimated front wave speed of the test pipe configuration. The relative mean errors reach a maximum of $33.5 \%$ for all the tested configurations.
4. The monitoring procedure consists of acquiring continuously the transient pressure signals and calculating the wave speed. Once a significant and persistent drop of the wave speed value is detected, a drop of the wall stiffness is suspected to occur somewhere along the shaft. The pressure FFTs should reveal a new peak at a frequency that corresponds to reflections from the weak reach. The wavelets approach is then used to locate the weakness and to estimate its severity. The state of the shaft with weak reach will be then considered as the basic configuration for future monitoring records. The reflections coming from other irregularities, such as galleries and caverns near the tunnel, and from partially closed valves can easily be discarded because of their known locations. The air pocket sources have a different pressure print out than the gradual drop of wall stiffness. They are characterized by a drastic and scattered drop of the wave speed. The roughness increase owing to corrosion of the liner is expected to have minor effect. A local significant change of the cross-section area of the tunnel can be caused by the yielding of liner steel after the loosening of its support.

In ongoing research, more laboratory experiments and in situ measurements will be carried out. The experiments will allow the validation of the localization procedure for different weak reach lengths and for more than one weak reach in the test pipe. It is also very interesting to examine the capabilities of such a procedure for localizing weak reaches on the basis of water-hammer waves with less steep front and less energy compared to those analyzed in this paper. The in situ measurements using dynamic pressure sensors at both ends of a pressure shaft of a pumped-storage power plant will give additional information about the steepness, energy, and dissipation of wave fronts generated during start-up and shut-down of pumps and turbines. The influence of the captured air inside the shaft on the estimation of the front wave speed will be also investigated.

\section{Acknowledgments}

The study is part of the research project HydroNet for the design, manufacture, and operation of pumped-storage plants funded by the Swiss Competence Center Energy and Mobility (CCEM-CH), the Swiss Electrical Research, and the Swiss Office for Energy. The writers wish to acknowledge the financial support of the Lombardi Foundation.

\section{Notation}

The following symbols are used in this paper:

$A=$ internal cross-sectional area of pipe or steel liner;

$A_{i}=i$ th-level approximation coefficient in wavelet decomposition;

$a=$ speed of sound in water or pressure front-wave velocity;

$a_{\text {basic }}=$ estimated mean front-wave speed of basic test pipe;

$a_{P 1, P 2}=$ estimated front-wave speed of test pipe configuration;

$a_{W R}=$ front-wave speed in water inside weak reach of pipes, penstocks, or steel-lined pressure tunnels;

$D=$ internal diameter of tunnel;

$D_{i}=i$ th-level detail coefficient in wavelet decomposition;

$d_{P 1, P 2}=$ distance between sensors $P 1$ and $P 2$;

$E=$ elasticity modulus;

$E_{\text {app }}=$ apparent elasticity modulus of rock mass;

$E_{s}=$ elasticity modulus of steel liner;

$e=$ pipe, penstock, or steel liner wall thickness;

$f=$ Darcy-Weisbach friction factor; 
$f_{a}=$ wavelet pseudofrequency;

$f_{c}=$ central frequency of $\mathrm{db} 10$ wavelet;

$f_{P 1, P 2}=$ frequency of propagating wave between sensors $P 1$ and $P 2$;

$f_{\max , P 1}=$ frequency at FFT maximum peak of $P 1$;

$f_{\text {max }, P 2}=$ frequency at FFT maximum peak of $P 2$;

$f_{s}=$ sampling frequency;

$f_{1 / 4 \text { front }}=$ quarter-frequency of wave front;

$g=$ acceleration because of gravity;

$h=$ piezometric head;

$h_{i}=$ piezometric head of incident pressure wave;

$h_{t} 1=$ piezometric head of transmitted pressure wave;

$h_{0}=$ steady-state piezometric head;

$j=$ level of wavelet decomposition;

$K_{w}=$ bulk modulus of water;

$L_{1}=$ estimated incident-reflection distance between weak reach and downstream reservoir;

$L_{2}=$ estimated incident-reflection distance between weak reach and upstream reservoir;

$l=$ path length of pressure wave;

$l_{W R}=$ estimated length of weak reach;

$m, n=$ positive integers;

$P 1=$ transient pressure records at sensor position $P 1$;

$P 2=$ transient pressure records at sensor position $P 2$;

$p=$ internal water pressure;

$r_{c}=$ external radius of pipe, penstock, or steel liner;

$r_{i}=$ internal radius of pipe or steel liner;

$s=$ wavelet dilation;

$t=$ time;

$t_{\text {int }}=$ time separating intersection point of regression line for steady-state pressure and regression line for first pressure front;

$t_{\max }=$ time of maximum front pressure;

$u=$ wavelet translation;

$u_{r}^{s}=$ radial displacement of steel liner;

$v=$ water-flow velocity;

$W f=$ continuous wavelet transform coefficients;

$x=$ longitudinal coordinate according to tunnel axis;

$\nu_{\text {Alu }}=$ Poisson's ratio for aluminum;

$\nu_{\mathrm{PVC}}=$ Poisson's ratio for PVC;

$\nu_{r m}=$ Poisson's ratio for the rock mass;

$\nu_{s}=$ Poisson's ratio for steel;

$\rho_{w}=$ unit mass of water; and

$\Psi_{u, s}=$ mother wavelet of translation $u$ and dilation $s$.

\section{References}

Al-Shidhani, L., Beck, S. B. M., and Staszewski, W. J. (2003). "Leak monitoring in pipeline networks using wavelet analysis." Key Eng. Mater., 245-246, 51-58.

Beck, S. B. M., Curren, M. D., Sims, N. D., and Stanway, R. (2005). "Pipeline network features and leak detection by cross-correlation analysis of reflected waves." J. Hydraul. Eng., 131(8), 715-723.
Bergant, A., Tijsseling, A., Vitkovsky, J., Covas, D., Simpson, A., and Lambert, M. (2008). "Parameters affecting water-hammer wave attenuation, shape and timing_Part 1: Mathematical tools." J. Hydraul. Res., 46(3), 373-381.

Chaudhry, M. H. (1987). Applied hydraulics transients, 2nd Ed., Van Nostrand Reinhold, New York.

Covas, D., Ramos, H., and Betâmio de Almeida, A. (2005). "Standing wave difference method for leak detection in pipeline systems." J. Hydraul. Eng., 131(12), 1106-1116.

Ferrante, M., and Brunone, B. (2003). "Pipe system diagnosis and leak detection by unsteady-state tests. 2. Wavelet analysis." Adv. Water Resour., 26(1), 107-116.

Fuentes, D. A. A., Galvis, L. F. C., and Valderrama, J. G. S. (2006). "Hydraulic transients with genetic algorithms used for leakage detection in real water distribution networks." Proc., Pipeline Division Specialty Conf. 2006: Pipelines-Service to the Owner, ASCE, Reston, VA.

Hachem, F. E., and Schleiss, A. J. (2009). "The design of steel-lined pressure tunnels and shafts." Int. J. Hydropower Dams, 16(3), 142-151.

Hachem, F. E., and Schleiss, A. J. (2011). "A review of wave celerity in frictionless and axisymmetrical steel-lined pressure tunnels." J. Fluids Struct., 27(2), 311-328.

Hunaidi, O. (2006). "New acoustic technology for non-destructive assessment of pipe wall thickness." Proc., Workshop on Performance and Cost Targets for Water Pipeline Inspection Technologies, AWWA Research Foundation, Denver, CO.

Halliwell, A. R. (1963). "Velocity of a waterhammer wave in an elastic pipe." J. Hydr. Div., 89(HY4), 1-21.

Lange, F. H. (1987). Correlation techniques, D. Van Nostrand, Princeton, NJ.

Liggett, J. A., and Pudar, R. S. (1992). "Leaks in pipe networks." J. Hydraul. Eng., 118(7), 1031-1046.

Mallat, S. G. (1990). A wavelet tour of signal processing, Academic Press, San Diego, CA.

Misiunas, D., Vitkovsky, J., Olsson, G., Simpson, A., and Lambert, M. (2005). "Pipeline break detection using pressure transient monitoring." J. Water Resour. Plann. Manage., 131(4), 316-325.

Parmakian, J. (1963). Waterhammer analysis, Dover, Mineola, NY.

Shamloo, H., and Haghighi, A. H. (2009). "Leak detection in pipelines by inverse backward transient analysis." J. Hydraul. Res., 47(3), 311-318.

Stephens, M. L., Simpson, A. R., and Lambert, M. F. (2008). "Internal wall condition assessment for water pipelines using inverse transient analysis." Proc., 10th Annual Symp. on Water Distribution Systems Analysis, ASCE, Reston, VA.

Streeter, V. L. (1963). "Discussion of 'Velocity of a water-hammer wave in an elastic pipe' by A. R. Halliwell." J. Hydraul. Div., 89(HY6), 295-296.

Taghvaei, M., Beck, S. B. M., and Boxall, J. B. (2010). "Leak detection in pipes using induced water hammer pulses and cepstrum analysis." Int. J. COMADEM, 13(1), 19-25.

Taghvaei, M., Beck, S. B. M., Boxall, J. B., Seth, A., and Staszewski, W. J. (2008). "Leak detection in water distribution network." Proc., 10th Int. Conf. on Pressure Surges, BHR Group, The Fluid Engineering Centre, Cranfield, UK, 125-135.

Timoshenko, S. P., and Goodie, J. N. (1970). Theory of elasticity, McGrawHill, New York.

Wylie, E. B., Suo, L., and Streeter, V. L. (1993). Fluid transients in systems, facsimile Ed., Prentice Hall, Englewood Cliffs, NJ. 